\title{
Process or Product? The Argument for Aesthetic Exploration in the Early Years
}

\author{
Deanna Marie Pecaski McLennan
}

Published online: 9 July 2010

(C) Springer Science+Business Media, LLC 2010

\begin{abstract}
Early childhood educators often deliberate the difference between the use of arts versus crafts in the classroom as learning opportunities. This paper discusses the distinct differences between the two and how encouraging young children to engage within art making provides great opportunity for personal and communal exploration, expression, and discussion. Open-ended activities that focus on the process, and not necessarily the end product, provide children with authentic, differentiated, and holistic methods of exploration and learning. Fostering a willingness to creatively engage within an aesthetic problemsolving process that allows children to select, represent, and explain their thoughts and actions will help them develop skills necessary for success in an unknown future.
\end{abstract}

Keywords Crafts - Art - Process - Product - Aesthetic . Exploration · Kindergarten · Early years · Preparation · Assessment

I recently completed an online early years additional qualification course designed for elementary teachers wishing to expand their knowledge of early years programs. One of the final topics of exploration was the use of visual art versus crafts in the classroom. We based our shared understandings of what each of these was by reading an online blog that discussed a possible difference between the two:

"A craft is usually a cookie-cutter or close-ended activity [that] is based on a formula or recipe and all

D. M. P. McLennan ( $₫)$

Elementary Educator, Windsor, ON, Canada

e-mail: dramaqueenbee@yahoo.ca participants follow the same directions and end up with roughly the same result every time. An art activity is more open-ended [and] is a work that transcends its humble materials to create an original statement or expression in a meaningful and enduring way." (Rayme 2006).

I read the ongoing discussion threads with great interest, as educators of all backgrounds and experiences passionately debated the differences between arts and crafts, and which of the two children should be creating in the classroom. My colleagues presented strong opinions for the value of including crafting in the classroom. "Crafts provide an opportunity for all children to create equally," "Crafts teach and practise fine motor skills," "Families appreciate receiving special crafts at holiday times like Christmas and Mother's Day." As I read the various statements of support and validation for the use of crafts in early years programs, I couldn't help but disagree. As a kindergarten teacher and dramatist, I have always encouraged students to use the materials available at the classroom arts centers (music, dramatic arts, and visual arts) in ways of their own devise. Rarely have we focused on the shape and form of the end product; rather it has been the experience of exploring and creating with the tools and materials appropriate to each that has been encouraged and celebrated. Although 'audience' appreciation of our classroom activities is welcomed, the opportunities with which we strive to provide our children have more to do with instilling a sense of empowerment and individuality in each child. As I reflected upon the art versus craft debate, I considered the validity of focusing on process versus product in early years classrooms and how children grow and develop aesthetically through exploratory experiences. 


\section{Artistic Process Versus Product}

As educators reflect upon personal philosophies and practices, they should consider the benefits for children in engaging in activities that focus on process rather than product. Regardless of whether children are engaged in music, visual arts, or dramatic arts there are very clear differences between whether an activity is centered on the experience itself or the final outcome. Whether the art is music (improvising a soundscape with instruments rather than singing along with a recording), visual arts (freeform sculpting with clay rather than pasting precut shapes onto a piece of paper), or dramatic arts (improvising during creative play rather than memorizing dialogue and actions for a play), comparing experiences to end results clearly reveal the depth of differences each activity provides to children. As educators make pedagogical decisions regarding the types of activities and experiences that will compose their program, they should be able to clearly and effectively articulate what, how, and why children do what they do in the classroom (Fullan et al. 2006; Saunders 2007). One is left to wonder what benefits exist for children when the purpose of their artistic endeavours is to create a similar piece as their peers or a replicate of their teacher's creation (closed ended 'art') or participate in the same way as the rest of their peers in an activity (scripted, choral performance). Reminiscent of Freire's "banking concept of education" (Freire 1970, p. 72) these types of activities encourage the student to become the "receptacle to be filled" with the information bestowed to them by the more knowledgeable teacher. When children participate in activities that encourage them to copy or produce an adult created or modeled activity, the scope of their creativity is limited, their interpretations of personal and peer work are greatly diminished, and the opportunity for them to enlighten others through a personal discussion of what and how was created is non-existent (Tarr 2001).

Vibrant classrooms are created when endless opportunities are available for children to become lost in art making, as educators embrace a "problem-posing model of education" (Freire 1970, p. 79) where learners are free to explore and experiment within multi-layered and multidisciplinary acts of cognition, teaching one another along the way (Bredekamp 1993; Dahlberg et al. 1999; Edwards et al. 1994). This exploratory art making creates "an educational culture that empowers students" (Howard 2004, p. 217) by encouraging them to think critically, to analyze their own realities, and to evaluate information presented to them by others (Howard 2004; Trend 1992). Educational spaces need to exist as "vibrant, living, creative spaces providing opportunities for dialogue and growth" among students and teachers (Haskell and Linds 2004). Openended activities provide children with authentic, differentiated, and holistic methods of exploration and learning (Booth and Masayuki 2004). Fostering a willingness to creatively engage within a problem-solving process that allows a child to select, represent, and explain his or her thoughts and actions will help develop skills necessary for an unknown future. "Today's students must be prepared unlike any generation before to think critically and analytically while acting with innovation and creativity." (Association for Supervision and Curriculum Development 2007). Educators today are preparing children so that they might be able to thrive in an unknown future. Encouraging and supporting aesthetic exploration in early years environments will help build a strong foundation for the creative thinking, problem solving, and reflexivity needed for growth and success in this unimaginable reality.

\section{Crafts Versus Arts}

Reflecting upon the discussion had in my Early Years course, the consensus among educators was that crafts are usually step-by-step activities that relate to a theme of exploration in the classroom. Unlike today's highly recognized and prized folk art (e.g., quilting, woodworking) that represents story, tradition, and craftsmanship, these closed-ended activities are devoid of meaning as they exist merely as utilitarian tasks meant to occupy students. A popular activity mentioned by many was the two-dimensional assembly of a paper animal's body when studying local habitats. Using pre-cut shapes a child engaging in this activity would be required to assemble the animal by gluing the pieces in the appropriate places in relation to the rest of the body. The head on top, the facial features within, and the appendages protruding in even spaces from the body. If assembled any differently than expected, it would be considered incorrect. In this example there is very little room for the imagination of the participating child, and none for interpretation and discussion by appreciators of the craft. The child either glues pieces in the correct or incorrect places. Other examples of crafts that were discussed include replicating designs or patterns using stickers or pre-cut shapes, cutting and pasting pictures from magazines, and colouring or painting photocopied pictures or precut paper shapes (e.g., heart, tree).

In any of these examples the emphasis is on the final result of the child's activities, or the product. There are some benefits for engaging students within more structured activities in the classroom that include exposure to a variety of techniques (e.g., mosaic, beading, patterning) and tools (e.g., scissors, brushes, pencils), practice of listening and observation skills (e.g., whether the activity could be completed as explained) and practice and refinement of fine motor skill. However, because there are very 
few choices or decisions made in the creation of the pieces, the activities usually engage children in more lower level thinking and diminished creativity than open-ended experiences might.

Many educators favour engaging children in prescribed crafting activities because they require all children to experience the same process while using identical tools and materials. A great number of teachers in my course felt as though crafts were something that 'needed to get done' so that the child could be assessed for reporting purposes. If the teacher modeled a craft and then each child was required to participate, it was a quick and easy way to ensure that everyone had an opportunity to complete the same activity and be assessed. Others felt the need to engage children in these rushed, empty activities due to outside pressure from other teachers and parents for the production of materials to decorate the classroom walls and fridges of children's homes (Tarr 2004). Crafts and arts were considered to be the same thing, without consideration of the difference in how each type of creation was made. However, I disagreed with this mentality. Children are unique and capable individuals who demonstrate their learning in differentiated ways. I wondered on what exactly children were being assessed 'on' when educators observe their 'art-making' skills-whether they can follow instructions; manipulate tools and materials in the manner modeled by their teacher; or orally repeat the steps taken in creating the piece? I believe that closed-ended activities are better used as cross-curricular experiences (e.g., assembling and labeling the human body at the science center) at various classroom centers instead of the main activity of the art area.

Unlike crafts, art activities have no predetermined end point. The final appearance of the piece is based on the sentiment or message the artist wishes to express through the medium. Sculpting with clay, painting with a variety of brushes and colours, and experimenting with prints are all examples of art experiences popular with early years children. Children form individual art pieces and each is influenced by their prior experiences and knowledge of art and life (Kindler 1995).

Books are the heart of an early years classroom and I have found my students to often be inspired by the stories we have read together. As a literacy extension they often design intricate pieces of artwork to help depict their evolved understandings and interpretations of the books. For example, Stranger in the Woods (Sams and Stoick 1999) uses real pictures to portray the story of animals who set out to discover who the stranger in their woods might be. After exploring it together, my students were inspired to create chalk and pastel drawings of winter landscapes. They used similar materials and techniques to create the illusion of winter in their pictures, but each piece was beautifully unique. The pieces expressed children's ideas of what might happen in the woods in the wintertime. As they created, they spent time alongside one another at the art center, engaging in lively discussions of what would be included in their picture and how they were going to accurately portray each.

As children engage in art-making together, it is the process of creating the art, and not just the final piece itself, that is valued (Bresler and Thompson 2002). Often children will engage in discussions with each other about the artwork and life itself as they work. Although the winter pictures the children created were aesthetically pleasing, what was more meaningful for me as an educator was what the children did while they engaged in the process of creating the piece. Discussions about the materials and tools (e.g., how to draw with the chalk to portray snow falling), the children's comprehension of the text (e.g., the elements of the story), and other aspects of real life important to the children (e.g., how they planned to play together at recess time) occurred throughout the art-making process. Focusing on the process still allows children an opportunity to use tools effectively, follow teacher instructions for the preparation and clean-up of materials, and practice fine motor control of materials.

One of the most interesting aspects of young children creating artwork is listening to them describe the process of how and why they made the piece the way they did. Appreciators will also be able to analyze and interpret the artwork, hopefully providing a catalyst for meaningful discussion to occur. Artwork can be assessed as easily as crafts. Direct observation can be used to watch and track children's use of materials and work habits throughout the art-making process. Children can also be questioned about their work using higher-level questioning techniques that require them to explain and interpret their artistic piece and process (Limbach and Waugh 2010). Varied opportunities for assessing art-making are possible throughout the aesthetic process. Whether a child can select materials, use the materials in innovative ways to create his or her piece, and engage others in a discussion about how and why they made what they did are all assessment opportunities.

Encouraging children to engage in frequent aesthetic exploration is possible when the arts are valued and encouraged in the classroom (Thompson 1995). Educators can emphasize various forms and mediums to students whenever possible (e.g., illustrations in a story, art within the school), present a variety of materials to choose from for use at the arts centers, and engage children in one-toone and small group creation in order to model and encourage participation in the complete process of artmaking. Using child-created artwork as decorations for the classroom in place of commercially bought bulletin board displays will also highlight to children that their work is 
meaningful to others (Tarr 2004). Posting a description of the piece using the artist's own words and adding pictures of him or her as the piece was made will emphasize the process. Consider your classroom space to be a living, blank canvas waiting to be embellished with students' creativity and innovation.

\section{Encouraging Aesthetic Knowledge and Engagement Through the Artistic Process}

When considering the craft versus art debate, one must consider that early development in children is shaped by their day-to-day experiences, helping to establish the pathways for successful lifelong learning (Best Start Panel on Early Learning 2007). Early years educators should seize each moment available to ensure that children are provided time and space to become lost in spontaneous, uninterrupted exploration, resulting in the acquisition of rich, aesthetic ideas. Aesthetic knowledge is described as the use of arts-based methods to construct knowledge in multiple subject areas. Children use senses such as hearing, seeing, smelling, tasting, and touching to create rich, sensuous, and personalized knowledge through artistic exploration (Abbs 1987). This type of arts-based learning provides an opportunity for young children to live in both an outer world, where they can realistically experience the creation of new knowledge, and an inner world, where reflection and internalization of the concepts are immersed into their very being. Lovat (2002) describes this artistic existence as a critical way of being and knowing in educational contexts, which encourages children to form their own ideas and opinions about the world around them, less restricted by the influence of their teacher's suggestions and opinions. Doing so provides children with endless opportunities to explore their own answers to questions and (re)question assumptions or facts presented by others. Children are able to critically and reflexively internalize information and create their own meanings and interpretations through personal experiences and interactions with the world around them. This experience becomes heightened when children work together, exploring and creating authentic and child-centered communal pieces.

Irwin (2004) argues that creating art is not something that is just done, but rather, is itself lived experience. The process of art making is not rehearsal for our representation of reality, but reality itself:

Thought and action are inextricably linked, and through a hermeneutic circle of interpretation and understanding, new knowledge affects existing knowledge that in turn affects the freshly conceived existing knowledge. (p. 34).
Art creation encourages each of us to live a life of deep meaning through perceptual practices that reveal what was once hidden, create what has never been known, and imagine what we hope to achieve through the "interweaving and intraweaving of concepts, activities and feelings." (Irwin 2004, p. 28) Irwin posits that active engagement in the arts provides participants an opportunity to experience three forms of thought: knowing, doing, and making. Engagement in the arts helps children to connect thought and action while collaborating creatively with others. This becomes a more powerful experience when the arts are combined, such as incorporating visual arts into a drama experience. Artists immerse themselves in "a collection of ideas, information, and artifacts" in order to "imagine and form different relationships amongst people and ideas." (Irwin 2004, p. 32) These interactions allow the artist to delve deeply into and explore the known, the unknown, and the imaginable.

\section{Encouraging Life-long Artists}

"Children are the living message we send to a time we will not see." (Postman 1994, p. xi)

When one considers the impact that educators and schools will have on the future, the experience of leading children in meaningful and engaging activities becomes of utmost importance. Every moment in the classroom counts and we as a society cannot afford for 1 minute to be wasted. Warlick's sentiment that "our schools are still, in too many ways, a reflection of past notions of what education is and what it looks like" (2009, paragraph 10) is a warning for educational stakeholders to reflexively consider their practice and whether classroom activities encourage higher-level, critical thinking such as art-making that "respects the creative impulses at work within the unfolding child" (Miller 2006, paragraph 5). When children are encouraged on a regular basis to explore the process, and not necessarily focus on the creation of a product, they become empowered to create personal, invested understandings about themselves and their places within the world. Progressing beyond the acquisition of simple, declarative knowledge, and instead providing ongoing opportunities for children to discuss, question, experiment, and actively engage within aesthetic frameworks will encourage students to "shun ideology, categorization, and fixed answers, and instead appreciate the flowing interrelatedness of all life" (Miller 2007, paragraph 4). It is possible for today's educators to help change tomorrow's world by the ways in which we respect and regard our children by providing regular opportunities for them to question, explore, and reflect through aesthetic exploration such as art making. After all, the best 
investment we can make for our society's future is in our children today (Pascal 2009).

\section{References}

Abbs, P. (1987). Living powers: The arts in education. London: Falmer.

Association for Supervision and Curriculum Development (ASCD). (2007). The learning compact redefined: A call to action. A report of the commission of the whole child. Retrieved 11 Oct 2009 from http://www.wholechildeducation.org/resources/Learning compact7-07.pdf.

Best Start Panel on Early Learning. (2007). Early learning for every child today: Framework for Ontario early learning settings. Toronto, ON: Ontario Ministry of Child and Youth Services.

Booth, D., \& Masayuki, H. (Eds.). (2004). The arts go to school. Toronto: Pembroke Publishers.

Bredekamp, S. (1993). Reflections on Reggio Emilia. Young Children, 49(1), 13-17.

Bresler, L., \& Thompson, C. M. (Eds.). (2002). The arts in children's lives: Context, culture, and curriculum. Dordrecht, The Netherlands: Kluwer Academic Publishers.

Dahlberg, G., Moss, P., \& Pence, A. (Eds.). (1999). Beyond quality in early childhood education and care: Postmodern perspectives. London: Falmer.

Edwards, D., Gandini, L., \& Forman, G. (Eds.). (1994). The hundred languages of children: The Reggio Emilia approach to early childhood education. Norwood, NJ: Ablex.

Freire, P. (1970). Pedagogy of the oppressed (Myra Bergman Ramos, Trans.). New York: Herder and Herder.

Fullan, M., Hill, P., \& Crevola, C. (2006). Breakthrough. Thousand Oaks, CA: Corwin Press.

Haskell, J., \& Linds, W. (2004). Enacting a space of possibility in education. Educational Insights, 9(1). Retrieved January 5, 2006 from http://ccfi.educ.ubc.ca/publication/insights/v09n01/articles/ intro.html.

Howard, L. A. (2004). Speaking theatre/doing pedagogy: Re-visiting theatre of the oppressed. Communication Education, 53(3), 217-233.
Irwin, R. L. (2004). A/r/tography: A metonymic metissage. In R. L. Irwin \& A. de Cosson (Eds.), A/r/tography: Rendering self through arts-based living inquiry. Vancouver, British Columbia: Pacific Educational Press.

Kindler, A. (1995). Significance of adult input in early childhood artistic development. In C. Thompson (Ed.), Visual arts and early childhood learning (pp. 10-14). Reston, VA: National Art Education Association.

Limbach, B., \& Waugh, W. (2010). Developing higher level thinking. Journal of Instructional Pedagogies, 3, Retrieved 8 June 2010 from http://www.aabri.com/manuscripts/09423.pdf.

Lovat, T. (2002). What is this thing called R.E. a decade on? (2nd ed.). Katoomba: Social Science Press.

Miller, R. (2006). Making connections to the world: Some thoughts on holistic curriculum. Encounter, 19(3). Retrieved 8 May 2009 from http://www.pathsoflearning.org/index.php.

Miller, R. (2007). A new culture needs a new education. Global Intelligencer. Retrieved 8 May 2009 from http://www.pathsof learning.org/index.php.

Pascal, C. (2009). With our best future in mind: Implementing early learning in Ontario. Report to the Premier by the special advisor on early learning. Toronto, ON: Queen's Printer for Ontario.

Postman, N. (1994). The disappearance of childhood. New York: Vintage Books.

Rayme, M. (2006). Art vs. Craft. Retrieved 8 Nov 2009 from http://www.suite101.com/blog/maryrayme/art_vs_craft.

Sams, C., I. I., \& Stoick, J. (1999). Stranger in the woods. Milford, MI: Carl R. Sams II Photography.

Saunders, L. (Ed.). (2007). Educational research and policy-making: Exploring the border country between research and policy. New York: Routledge.

Tarr, P. (2001). Aesthetic codes in early childhood classrooms: What art educators can learn from Reggio Emilia. Art Education, 54(3), 33-39.

Tarr, P. (2004). Consider the walls. Young Children on the Web. Retrieved 8 June 2010 from http://www.naeyc.org/files/yc/file/ 200405/ConsidertheWalls.pdf.

Thompson, C. (Ed.). (1995). Visual arts and early childhood learning. Reston, VA: National Art Education Association.

Trend, D. (1992). Cultural pedagogy: Art/education/politics. New York: Bergin \& Garvey. 